\title{
An Analysis of Dampness Study on Heritage Building: A Case Study Ipoh Old Post Office Building and Suluh Budiman Building, UPSI, Perak, Malaysia
}

\author{
Al-Hafzan Abdullah Halim \\ Department of Building Surveying, Faculty of Architecture, Planning and Surveying \\ University Technology MARA Perak, Seri Iskandar Campus \\ 32610 Bandar Baru Seri Iskandar Perak, Malaysia \\ Tel: 60-5-374-2403 E-mail: alhaf689@perak.uitm.edu.my \\ Anas Zafirol Abdullah Halim \\ Department of Building, Faculty of Architecture, Planning and Surveying \\ University Technology MARA Perak, Seri Iskandar Campus \\ 32610 Bandar Baru Seri Iskandar Perak, Malaysia \\ Tel: 60-5-374-2433 E-mail: anaz607@perak.uitm.edu.my
}

\begin{abstract}
Analysis of dampness covers a variety of methods for measuring moisture content in both high level and trace amounts in solids such as building element. Analysis of dampness in heritage building is very important to avoid serious damage in heritage property. One of the heritages building in Perak is Ipoh Old Post Office Building and the other heritage building in Perak is Suluh Budiman Building at UPSI. Ipoh Old Post Office Building and Suluh Budiman Building are historical buildings which show the colonial's features and European architecture. From the site observation, a lot of defects occurred in these buildings had been identified during the investigation and some minor defects can be seen in almost every part of the building. High moisture content or dampness at heritage wall had caused almost every part of the building experienced a very serious defect and a prompt action must be taken before the increasing of cost implication. Hence, a study on moisture before conducting any conservation and repair work is needed and it is very important to help the conservator and building environmental designer to analyze and understand the exact sources of dampness's problem correctly and effectively. The correct analysis of dampness on heritage building will produce the best method to overcome the sources and the actual dampness problem in heritage building generally.
\end{abstract}

Keywords: Ipoh old post office building, Suluh Budiman building, Dampness analysis, Heritage building and conservation works

\section{Introduction}

Nowadays, Ipoh Old Post Office building is in obsolete condition and a lot of renovation works had been operated without any guidance by conservation principles. Building conservation according to The Encyclopedia of Malaysia Architecture (1998) can be defined as the action to prevent decay, embracing all acts that prolong the life of historic buildings. Building conservation relates specifically to the process of preservation and restoration of building materials, which aims to prolong a building's life and function. Some of these historic buildings in Malaysia are structurally sound and have undergone physical transformations to adapt to climatic conditions as well as the local way of life. However, with the country's current rapid development in which the practice of demolishing old buildings has been a normal scenario, it is important to identify the old record, preserve and conserve the British Colonial Buildings. Even though the number of these buildings in Malaysia is relatively small as compared to other indigenous buildings, conservation of such historic buildings should be seen as representing a particular aspect of Malaysia's history and development. British Colonial Buildings should be conserved and preserved properly because of sensitivity towards the past including historical and aesthetics value, emotional ties, continuity and stability of physical surroundings, the absence of protection against economic pressure, and the importance of tourism to the country economy and lower estimated cost of development. That is why the conservation works are very important to be carried out properly. S.N. Harun and K. S. Kamal (2002) found that building conservation project includes certain phases to be carried out. There are four phases included in conservation projects before the building is exposed to any repair work or refurbishment work which are documentation, building investigation, building diagnosis and conservation and repair techniques. In 2004, Ghafar reported that dampness penetration through walls can be a serious matter, particularly to buildings located near water sources. Not only does it deteriorates building structures but also damages the furnishings. The main cause of dampness is water entering a building through different routes. Water penetration occurs commonly through walls exposed to prevailing wet; wind or rain. With the existence of gravity, water may penetrate through capillaries or cracks between mortar joints, and bricks or blocks before building up trap moisture behind hard renders. Water may also drive further up the wall to emerge at a higher 
level. Dampness also occurs in walls due to other factors such as leaking gutters or downpipes, defective drains, burst plumbing and condensation due to inadequate ventilation. Dampness may also enter a building from the ground through cracks or mortar joints in the foundation walls. High level of dampness will trigger a lot of problems to the heritage building and it will give negative consequences to the building material and finishes. Ipoh Old Post Office building, is located near Town Hall Building at Jalan Dato' Sagor, Ipoh Perak, Malaysia. In front of this building is Medan Selera Dato' Sagor while on the left side of this building is the state mosque. This building was completely built in 1916. Suluh Budiman Building is located at Universiti Pendidikan Sultan Idris (UPSI). It is the oldest building at Tanjung Malim. The construction was started at 1919 and was officially opened at November 1922.

\section{$<$ Photo 1: Ipoh Old Post Office Building in 2009> \\ $<$ Photo 2 : Suluh Budiman Building in 2009>}

\section{Work Procedures and Dampness Study}

According to this study, there are several procedures that must be followed. There are two protocols of diagnosis that have been applied for this study which are visual inspection protocol and non-destructive test. These protocols are categorized in dampness study for the first procedure, surveying equipment as the second procedure, work method as the third procedure and reference code as the last procedure. Dampness study was conducted by using two types of protocols which are visual inspection and non-destructive test. Visual inspection was conducted through observation of surrounding area, checking out the damp zone and prediction of suspected causes. The equipment that had been used to do non-destructive test for dampness level is Moisture Meter. The measurement of dampness would focus on defected wall by looking at its symptom such as blistering, chalking, staining and so forth. There were forty identified locations that had been selected by the contractor and the level of dampness had been tested.

\section{Work Method and Reference Code}

Moisture meter was allocated at wall which has high level of dampness. 9-10 points had been tested for one location of wall to predict the movement of water penetration to ease the detection of the sources of dampness. Then, the reading was taken and noted at checklist. The result was analyzed to detect the sources of dampness. For this study, there were three readings of moisture meter (relative humidity $\mathrm{rH}$ ) which were:

1) Low level of dampness, between $6 \% \mathrm{rH}-16 \% \mathrm{rH}$.

2) Intermediate level of dampness, between $18 \% \mathrm{rH}-21 \% \mathrm{rH}$.

3) Serious level of dampness between $22 \% \mathrm{rH}-100 \% \mathrm{rH}$

The Table 3.1 shows the number of location for each part of the building that has been tested by using moisture meter. For example, for the first floor at internal wall, sixteen (16) numbers of location were tested by moisture meter while eleven (11) locations were tested on the external floor. The total location that had been tested was forty (40). < Table 3.1: Total Location of Non-Destructive Test >

The reference code was used as guidance in work process. The reference codes assist in showing the location of dampness in measured drawing plan and checklist; besides, it will be shown in the report to assist client for better understanding about the dampness and its location at the actual site. Table 3.2 below shows the reference codes that have been applied to identify the tested location.

\section{e.g.: TB/X1 < Table 3.2: Reference Codes That Have Been Used in Dampness Study >}

\section{Dampness Analysis in Ipoh Old Post Office Building}

\subsection{Rising Damp}

Rising damp occurs as a result of capillary suction of moisture from the ground into porous masonry building materials such as stone, brick, earth and mortar. The moisture evaporates from either face of the wall (inside or outside), allowing more to be drawn from below. The height to which the moisture will rise is determined by the evaporation rate and the nature of the wall. The normal limit for rising damp ranges from 0.5 to 1.5 meters above ground level. Rising damp may show as a high-tide-like stain on wallpaper and other interior finishes, and, when it is severe, as blistering of paint and loss of plaster. Damp walls encourage the growth of moulds, which, with high humidity, can lead to health problems to occupants. Externally, a damp zone may be evident at the base of walls, with associated fretting and crumbling of the masonry. On its own, rising damp can make buildings unsightly and unpleasant to occupy. The situation is much worse if there are appreciable quantities of soluble salts present, for the rising damp will carry salts up into the masonry to where the damp evaporates. Then, the salts are left behind and can often be seen as a white efflorescence on the wall surface. When these salts grow as crystals within the pores of the masonry they can disrupt even the strongest material, leading to fretting and crumbling of the surface. This process is known as salt attack, and, when it is severe, it can lead to slow but complete loss of stones and bricks in a wall. For this building, rising damp occurs at internal and external wall which are 16 identified areas for internal wall while 6 areas for external wall. Photo 4.1 and Photo 4.2 below show the symptoms of rising damp at this building while Table 4 shows the affected location. < Table 4.1: Location of Rising Damp> 


\subsection{Roof Leakage}

Roof structure experiences the most serious defect. Roof covering is broken and had caused the building to be exposed to the rain and sunlight. Wood structure decayed and faces termite attack seriously. Besides, the bonding between lime plaster and surface of bricks became weak because of long exposure of dampness. The surface was brittle, flaking and blistering. On the other hand, the wall is also affected by mould and fungus attack, these can be seen at 8 locations selected by the contractor at the first level. The reading of moisture meter showed the aptly frequency which is the wall below is higher than the above wall. Photo 4.3 and Photo 4.4 show several locations experience the same defect while Table 5 below shows the defected location. < Table 4.2: Location of Roof Leakage $>$

\subsection{Plaster Crack}

There are hairline crack occurs on wall lime plaster which means the existence of capillary effects that cause water penetration into building wall. In this study, there are three (3) locations of plaster crack. Photo 4.5 and Photo 4.6 show the plaster cracks occur on wall and Table 4.3 below shows affected locations. < Table 4.3: Location of Plaster Crack >

\subsection{Defective Rainwater Goods (RWDP)}

Rainwater goods such as rainwater down pipes are not functioning properly. Most of the rainwater goods are broken, decayed, corroded and damaged so badly. This situation will cause inappropriate water flow and the surface of the wall and floor are highly moisture and attacked by fungus. The inappropriate water flow leads to the crack of parameter drain. In this study, there are six (6) identified locations effected by defective rainwater goods. Photo 4.7 and Photo 4.8 show several problems occurred caused by design deficiency of rainwater down pipes and Table 7 shows overall area defected by the same causes. < Table 4.4: Location of Defective Rainwater Goods (RWDP) >

\subsection{Pipe Leakage}

The leakage of clean water supply pipe that has been buried inside the building components also happened in this case study. There is only one (1) location affected which is at grid: B/2 (Y10) where the water was easily flowing at the buried pipe. The moisture meter showed the increasing reading close to the location of dampness which is $70.9 \% \mathrm{rH}$. Photo 4.9 shows the defected location.

\subsection{Driving Rain}

Driving rain always occurs at the exposure area, the effect of driving rain will cause high level of dampness at a wall. The material of wall is derived from lime and bricks. The property of lime such as porous will lead to penetration of rain water and from the environment. For this building, three (3) locations have been identified caused by driving rain. Photo 4.10 shows the defected area and symptom and table 9 shows the overall defected locations. < Table 4.5: Location of Driving Rain >

\section{Dampness Analysis in Suluh Budiman Building}

Moisture problem in Suluh Budiman Building is caused by several factors such as roof leaking and the driving rain from defective rainwater goods. There are Four (4) high moisture reading identified locations. First location is at internal wall, the dampness can be seen from the symptom itself such as humid, paint blistering and chipping while the lime plaster crumbled. The temperature is about $29^{\circ} \mathrm{C}$. The causes of defect are leaked roof structure, broken roof tile and defective rainwater goods. Photo 5.1 below shows high reading of moisture meter at internal wall.

From the above reading of moisture meter, the highest moisture content is $96.4 \% \mathrm{rH}$, the dampness can be detected from top to bottom. Photos 5.2 below show the several causes that contributed to wall dampness.

Internal wall near to the arch also experience the same defects. The surface of wall was partially covered by moss and fungus while another defect is paint flaking. This matter happen because of water from top had penetrated into mortar joint and ceiling to cause ceiling decay. Refer Photo 5.3

From the above reading of moisture meter, the highest moisture content is $86.6 \% \mathrm{rH}$. The dampness can be detected from roof. Photo 5.4 below shows the several causes that contributed to wall dampness and its effects.

Next location is at external wall, unwanted plant such as ficus and fungus attacked the surface of column and wall. This matter happened because of design deficiency of rainwater goods. Refer Photos 5.5

From the above reading of moisture meter, the highest moisture content is $91.6 \% \mathrm{rH}$. The dampness can be detected from roof structure. The best way to overcome this problem is by doing repair work of rainwater pipes and planned maintenance must be done after conservation works completed.

The last location of dampness is situated at external wall at rear side of the building. The defect of the wall is caused by rising damp, the crack at the drainage parameter and apron contributed to moisture penetration. The height of rising damp is about $800 \mathrm{~mm}$. Photo 5.6 below show the reading of moisture meter.

From the above reading of moisture meter, the highest moisture content is $100 \% \mathrm{rH}$. The moisture had caused 
high dampness on wall, paint blistering, broken drainage and cracking at apron. Photos below show the symptoms of moisture penetration through wall and its effects. Refer photos 5.7

\section{Discussions and Recommendation}

Hence, some considerations must be taken to find out the exact remediation to control and prevent dampness from happening again. For Ipoh Old Post Office Building, the dampness occurs from several causes such as rising damp, roof leakage, plaster cracking, defective rainwater goods, pipe leakage and driving rain. All defected area caused by dampness can be prevented via effective design and proper planned maintenance. The detection of exact method of remediation is very important to make sure no repeated defects occur.

\subsection{Internal Wall (Ground Floor)}

Overall condition of internal wall for ground floor level experience rising damp. The properties of salt can penetrate water that can cause water movement from bottom of wall to top level of wall. For this building, the preferment of water is between $1.2 \mathrm{~m}$ until $1.5 \mathrm{~m}$ from the bottom of wall. Water movement penetrated to the most salty area of the wall. The recommendation to overcome rising damp matter is by using 'Chemical Damproof System Technique' and 'Cocoon' techniques. For cocoon technique, the paste must bond properly to the surface to be treated. Thus, the surface must be sound and swept clean of salt, dust, sand or loose fragments. Special precaution is to be taken where the surface is delicate and/or easily detached. After that, the material applied to the bricks surface to be desalinated as poultice is $5 \mathrm{~mm}$ to $10 \mathrm{~mm}$ thick according to the type of the surface by means of a spatula or by spraying. The quantity recommended is normally 6 to $7 \mathrm{~kg}$ of wet materials per square metre. The poultice is left to perform its action for about 2 weeks. After drying, the paste becomes cardboard mould which can be peeled off from substrate and disposed of. After that, the technique will be continued by using 'Chemical Damproof Course System' technique. On the commencement of a typical rising damp project, the applicator removes the original skirting. Skirting may be refitted after the installation of the chemical damp proof course and the completion of the replastering. In some cases the skirting may be rotten and require replacement. The damp effected plaster is then removed to expose the bricks. After selecting the course of the brick which will become the new damp proof course, a series of $10 \mathrm{~mm}$ holes are drilled at an appropriate depth and spacing. The injection lances are then introduced into the holes and a seal is formed by a rubber expansion washer which holds the lance firmly into the brick. The injection fluid is then pumped via flexible tubing into the brick work and the fluid, now under pressure, is forced through the capillaries of the brick until it is visually evident that saturation has taken place. The lances are then removed and the procedure is repeatedly progressing along the wall to be treated. The injection fluid continues to penetrate through mortars joints by capillary for approximately 24 hours. After the full thickness of the wall is injected the continuous saturated section of brick will become the new damp proof course. After a short drying period the walls may be replastered to complete the job.

\subsection{External Wall (Ground Floor)}

Based on the high level of dampness reading from moisture meter in several parts of walls, there are some problem exists in this building related to dampness itself:

i. There are several locations experiencing rising damp problem

ii. Design deficiency of rainwater down pipe

iii. Roof covering ruined and leakage: Refer to Photo 6.1

iv. Not enough projection of roof structure to avoid heavy driving rain, Refer to Photo 6.2

v. Too much exposure from the weather such as direct sunlight and rain and the failure design of roof. Refer to Photo 6.3

vi. The arrangement of roof tile is not properly done and rain water easily penetrates into the building. Refer to Photo 6.4

vii. Parameter drain was badly damaged due to settlement and caused the water to easily penetrate under the floor and it makes the sand bed removed from its place. Refer to Photo 6.5 and Photo 6.6.

Thus, the recommendation of remediation is needed such as:

i. Repair and redesign the new rain water down pipe as well as gutter system. It must be functioning well with maintenance prediction and try to avoid the increasing of maintenance cost.

ii. Redesign the projection of roof structure to reduce driving rain's effects and direct sunlight.

iii. Some locations with high level of dampness require 'Chemical Damproof System Technique' and 'Cocoon' techniques.

iv. Replace and rearrange the roof tiles.

6.3 Internal and External Wall (First Floor)

There are varieties of causes of dampness that occur on this floor level. The factors that contribute to the dampness of this floor are:

i. The leaking of roof covering- Roof structure experience the most serious defect. The components of building from timber such as window, door and floor are seriously defected such as decayed due to exposure from dampness and weather effect. 
ii. Photo 6.7 and Photo 6.8 show a tree grew before it was trimmed. While Photo 6.9 and Photo 6.10 show the condition after the tree was trimmed. That situation had lead to the highest level of dampness in this building.

iii. There are hairlines cracks occur in the wall that lead to the water penetration by water movement in the capillaries. Refer to Photo 6.11

iv. Minor cracks on the floor can be seen from the flat roof that acts as a floor balcony on the top floor. Refer to Photo 6.12 .

Thus, the roof needs to be repaired to avoid negative consequences. So, a temporary roof must be built to prevent rainwater penetration.

\subsection{Suluh Budiman's Result and Method of Repair}

Dampness problem in Suluh Budiman Building are in moderate level. Defected area is caused by existing defects and design deficiency including no planned maintenance at all. Suggestions of conservation method are as follows:

1) Restore roof leakage such as replace critical part of tile that broken and lost.

2) Repair rain water pipe and gutter by replacing damaged gutter, leak and extend of rainwater pipe and channel properly to drain.

3) Repair drains parameter system and apron. Main task is to remove the precipitation such as mud, plant and rubbish which contribute to blockade in drain parameter.

4) Knock cracked surface and restore apron such as original shape.

5) Replace the broken and cracked drain with new drain and corresponding drainage system.

6) Ensure all work (i and ii) have been completed then wall's conservation is started. This is to ensure damp wall has really dry.

7) The crumbled wall plaster need to be knocked slowly to produce loose plaster until it clean

8) Wall that had been clean must be plastered again with new plaster material which has same material and composition to get corresponding appearance and surface.

\section{Conclusions}

As a conclusion, there are several factors contribute the high level of dampness in these buildings, from the study, several factors were identified such as rising damp, roof leaking, hairline cracks occur on the lime plaster, heavy driving rain and design deficiency of roof and rainwater goods. The dampness defects occur due to roof leaking and it penetrate through cracked wall while the ther dampness is due to rising damp. Thus, recommendation that should be used for Ipoh Old Post Office building is 'Chemical Damproof System Technique' and 'Cocoon' techniques and another methods stated above to overcome the dampness problem in this building while for Suluh Budiman Building, recommendation that should be used is repair and restore roof structure, rainwater goods and repair parameter drain.

\section{References}

A Ghafar Ahmad. (2004). Heritage Conservation, Understanding Common Building Defects. Majalah Akitek, Volume 16, Issue 1, First Quarter 2004, pg. 19-21.

Badrul Hisham Arkitek. (2008). Laporan Kajian Dilapidasi dan Cadangan Skop Kerja Pemuliharaan Bangunan Pejabat Pos Lama Ipoh.

Burden, E. (2004). Illustrated Dictionary of Architectural Preservation: Restoration, Renovation, Rehabilitation and Reuse. McGraw Hill, New York.

Jabatan Ukur Bangunan, UiTM Perak. (2009). Laporan Ujian Kelembapan Bangunan Pejabat Pos Lama Ipoh. Jabatan Ukur Bangunan, Universiti Malaya. (2007). Building Condition Survey in Malacca High Court.

Najcom Sendirian Berhad. (2004). Laporan Rawatan Cocoon untuk Kerja-kerja Pemuliharaan, Bangunan No. 116 \& 118 , Lebuh Acheh, Pulau Pinang.

S.N. Harun and K. S. Kamal. (2002). Building Research Methodology in the Conservation of the historic building, International Symposium Building Research and the Sustainability of the Built Environment in The Tropics, University Tarumanagara, Jakarta Indonesia, 14 -15 October 2002. 
Table 3.1 Total Location of Non-Destructive Test

\begin{tabular}{|l|c|}
\hline Wall Location & Number of Area \\
\hline First Floor & 16 \\
\hline a. Internal Wall First Floor & 11 \\
\hline b. External Wall First Floor & 5 \\
\hline c. External Column First Floor & \\
\hline Second Floor & 2 \\
\hline a. Internal Wall Second Floor & 5 \\
\hline b. External Wall Second Floor & 1 \\
\hline c. External Column Second Floor & $\mathbf{4 0}$ \\
\hline Total & \\
\hline
\end{tabular}

Table 3.2 Reference Codes that have been Used in Dampness Study

\begin{tabular}{|c|c|}
\hline Code & Explanation \\
\hline TB & First Floor \\
\hline TS & Second Floor \\
\hline TL & External Column \\
\hline $\mathrm{X}$ & Internal Wall \\
\hline Y & External Wall \\
\hline
\end{tabular}

Table 4.1 Location of Rising Damp

\begin{tabular}{|c|c|c|c|}
\hline Element & Level & Locations (Grid) & Checklist \\
\hline Internal Wall & First Floor & $\mathrm{G} / 5-6(\mathrm{X} 1)$ & 1 \\
& & $\mathrm{G} / 6-7(\mathrm{X} 2)$ & 2 \\
& & $\mathrm{E} / 7-8(\mathrm{X} 3)$ & 3 \\
& & $\mathrm{G} / 5-6(\mathrm{X} 4)$ & 4 \\
& & $\mathrm{E} / 4-5(\mathrm{X} 5)$ & 5 \\
& & $\mathrm{E}-\mathrm{F} / 5-6(\mathrm{X} 6)$ & 6 \\
& $\mathrm{C}-\mathrm{D} / 4(\mathrm{X} 7)$ & 7 \\
& & $\mathrm{D} / 4(\mathrm{X} 8)$ & 8 \\
& & $\mathrm{D} / 6(\mathrm{X} 9)$ & 9 \\
& & $\mathrm{~B} / 4(\mathrm{X} 10)$ & 10 \\
& & $\mathrm{D} / 8(\mathrm{X} 11)$ & 11 \\
& & $\mathrm{~B} / 7-8(\mathrm{X} 12)$ & 12 \\
& & $\mathrm{~F} / 8(\mathrm{X} 13)$ & 14 \\
& & $\mathrm{D} / 8(\mathrm{X} 14)$ & 15 \\
& & $\mathrm{C} / 11(\mathrm{X} 15)$ & 16 \\
\hline External Wall & First Floor & $\mathrm{D} / 11(\mathrm{X} 16)$ & 20 \\
& & $\mathrm{H} / 8-9(\mathrm{Y} 4)$ & 21 \\
& & $\mathrm{G}-\mathrm{H} / 5(\mathrm{Y} 5)$ & 23 \\
& & $\mathrm{D}-\mathrm{E} / 3(\mathrm{Y} 7)$ & 24 \\
& & $\mathrm{D} / 5(\mathrm{Y} 8)$ & 27 \\
\hline
\end{tabular}

Table 4.2 Location of Roof Leakage

\begin{tabular}{|c|c|c|c|}
\hline Element & Level & Location (Grid) & Checklist \\
\hline Internal Wall & Second Floor & $\mathrm{G} / 7-8(\mathrm{X} 1)$ & 33 \\
& & $\mathrm{G} / 5-6(\mathrm{X} 2)$ & 34 \\
\hline External Wall & Second Floor & $\mathrm{G} / 7-8(\mathrm{Y} 1)$ & 35 \\
& & $\mathrm{G} / 5-6(\mathrm{Y} 2)$ & 36 \\
& & $\mathrm{~B} / 7-8(\mathrm{Y} 3)$ & 37 \\
& & $\mathrm{~B} / 9-10(\mathrm{Y} 4)$ & 38 \\
& & $\mathrm{C} / 11(\mathrm{Y} 5)$ & 39 \\
\hline
\end{tabular}


Table 4.3 Location of Plaster Crack

\begin{tabular}{|c|c|c|c|}
\hline Element & Level & Location (Grid) & Checklist \\
\hline Internal Wall & First Floor & $\mathrm{G}-\mathrm{H} / 5(\mathrm{Y} 5)$ & 21 \\
\hline External Wall & Second Floor & $\mathrm{B} / 7-8(\mathrm{Y} 3)$ & 37 \\
& & $\mathrm{~B} / 9-10(\mathrm{Y} 4)$ & 38 \\
\hline
\end{tabular}

Table 4.4 Location of Defective Rainwater Goods (RWDP)

\begin{tabular}{|c|c|c|c|}
\hline Element & Level & Location (Grid) & Checklist \\
\hline External Wall & First Floor & $\mathrm{E} / 5(\mathrm{Y} 1)$ & 17 \\
& & $\mathrm{E} / 7(\mathrm{Y} 2)$ & 18 \\
& & $\mathrm{D} / 8(\mathrm{Y} 3)$ & 19 \\
& & $\mathrm{E} / 4(\mathrm{Y} 6)$ & 22 \\
\hline External Column & First Floor & $\mathrm{A} / 9$ (TL1) & 28 \\
& & $\mathrm{~A} / 11$ (TL2) & 29 \\
\hline External Column & Second Floor & $\mathrm{D} / 12$ (TL1) & 40 \\
\hline
\end{tabular}

Table 4.5 Location of Driving Rain

\begin{tabular}{|c|c|c|c|}
\hline Element & Level & Location (Grid) & Checklist \\
\hline External Column & First Floor & B/12(TL3) & 30 \\
& & G/12(TL4) & 31 \\
& & H/11(TL5) & 32 \\
\hline
\end{tabular}

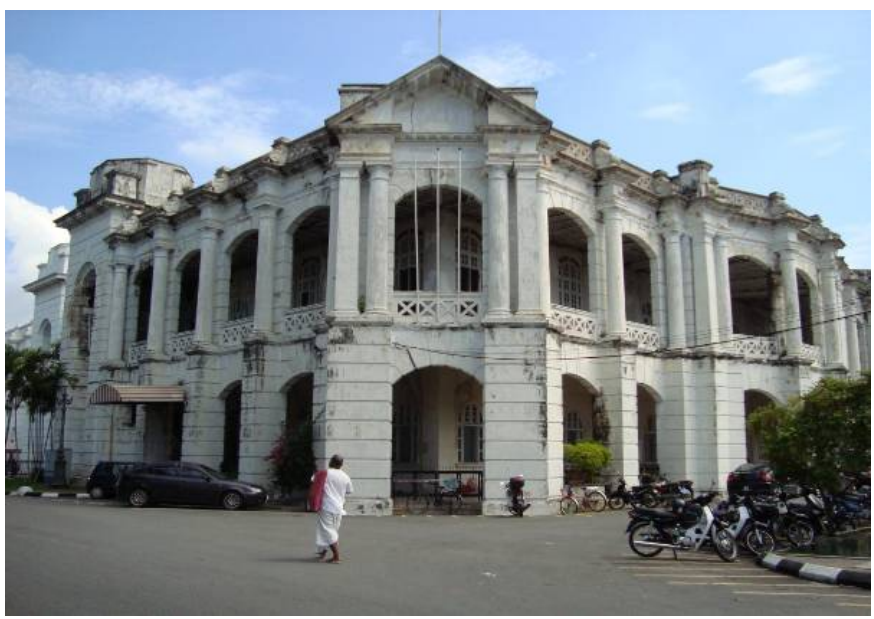

Photo 1. Ipoh Old Post Office Building in 2009

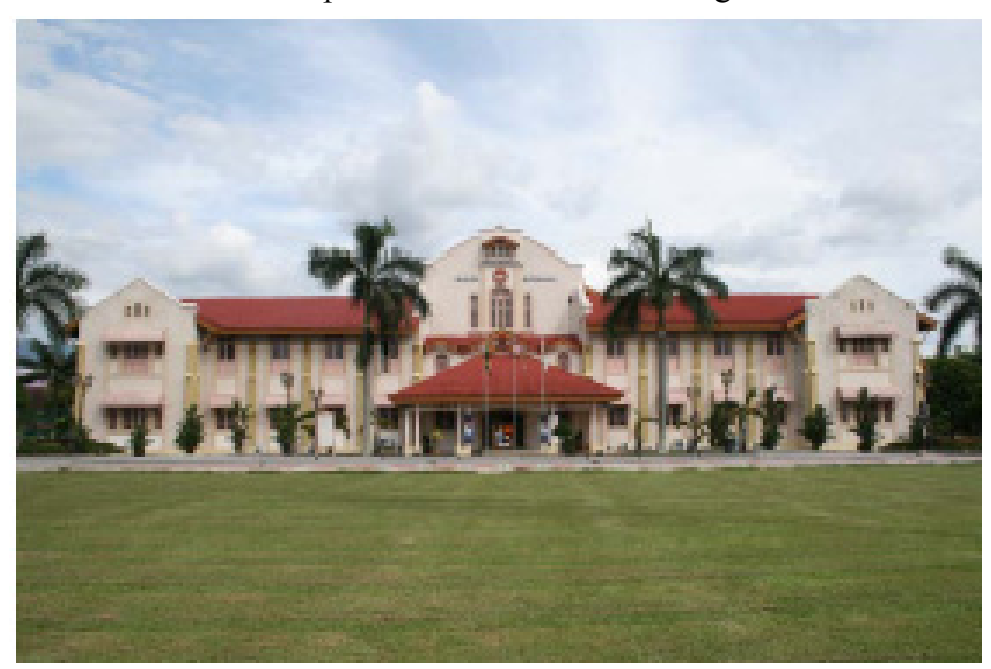

Photo 2. Suluh Budiman Building in 2009 


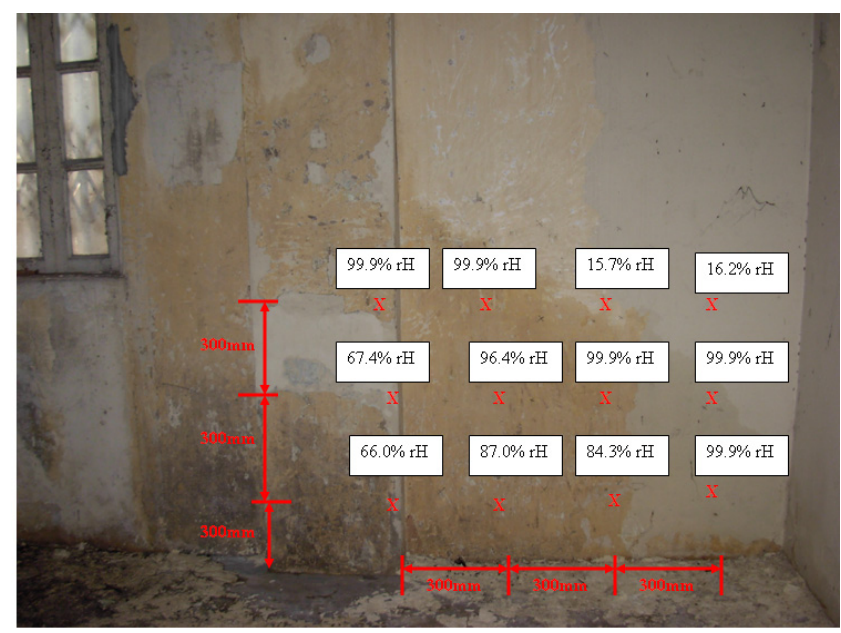

Grid: B/7-8 (X12), Checklist 12

Photo 4.1 Symptom of Rising Damp

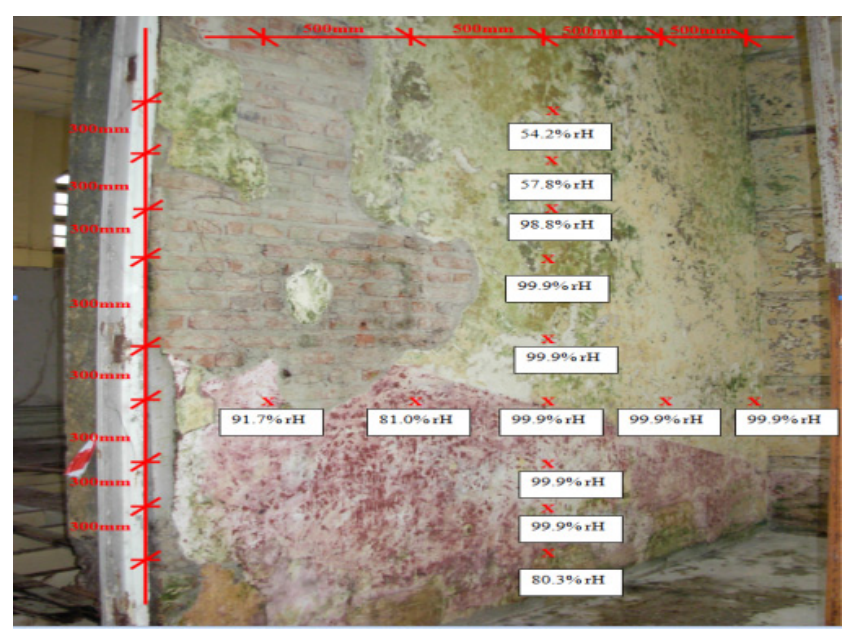

Grid: G/7-8 (X1), Checklist 33

Photo 4.3 Fungus and Mould Attack

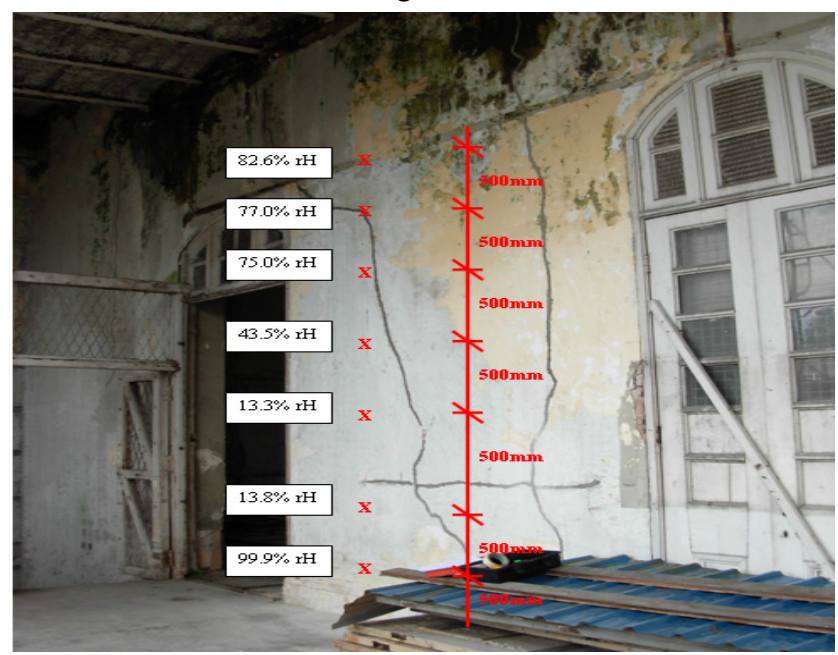

Grid: B/7-8 (Y3), Checklist 37

Photo 4.5 Minor Cracks Along Wall Plaster

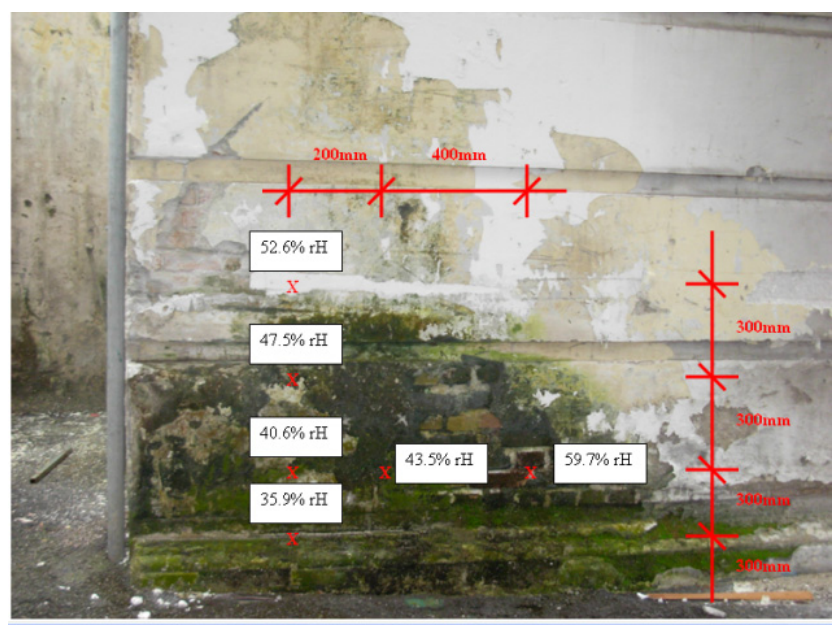

Grid: C-D/3-4 (Y9), Checklist 25

Photo 4.2 Wall Attacked by Fungus

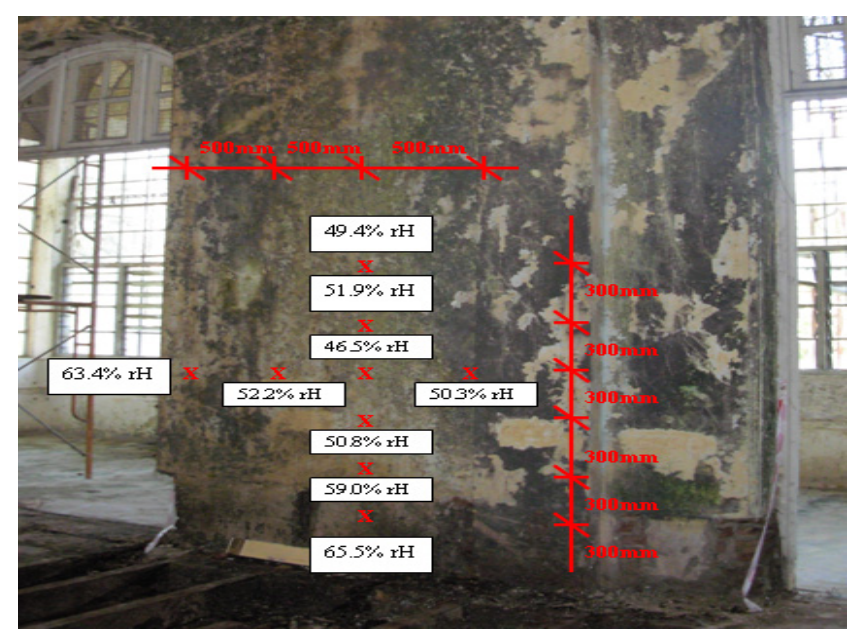

Grid: G/5-6 (Y2), Checklist 36

Photo 4.4 Wall Wet and Damp

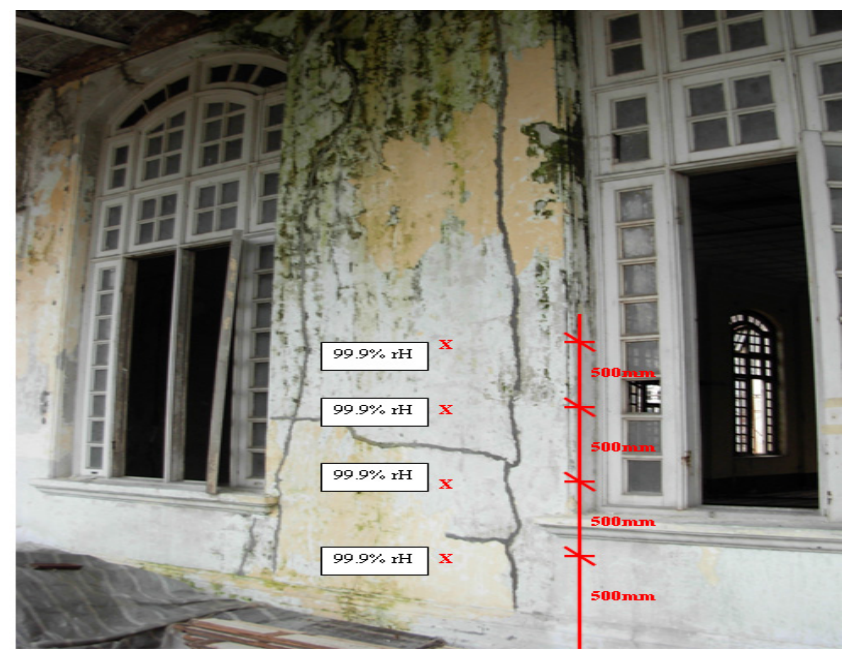

Grid: B/9-10 (Y4), Checklist 38

Photo 4.6 Vertical Cracks 


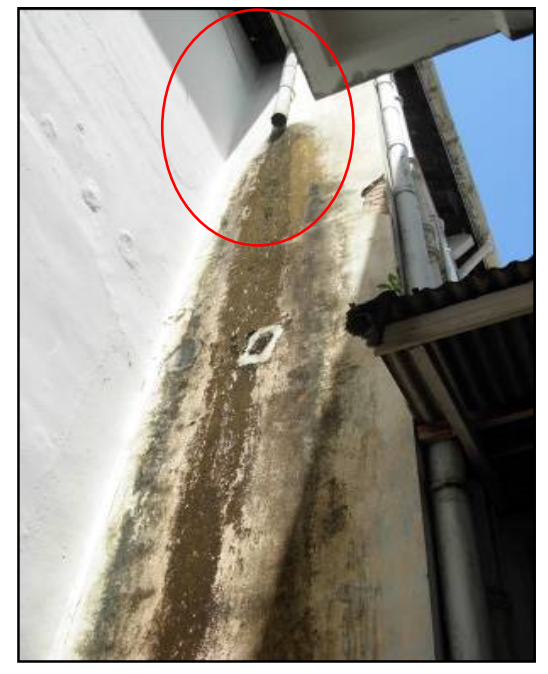

Grid: E/4 (Y6), Checklist 22

Photo 4.7 Inefficient of RWDP Effect

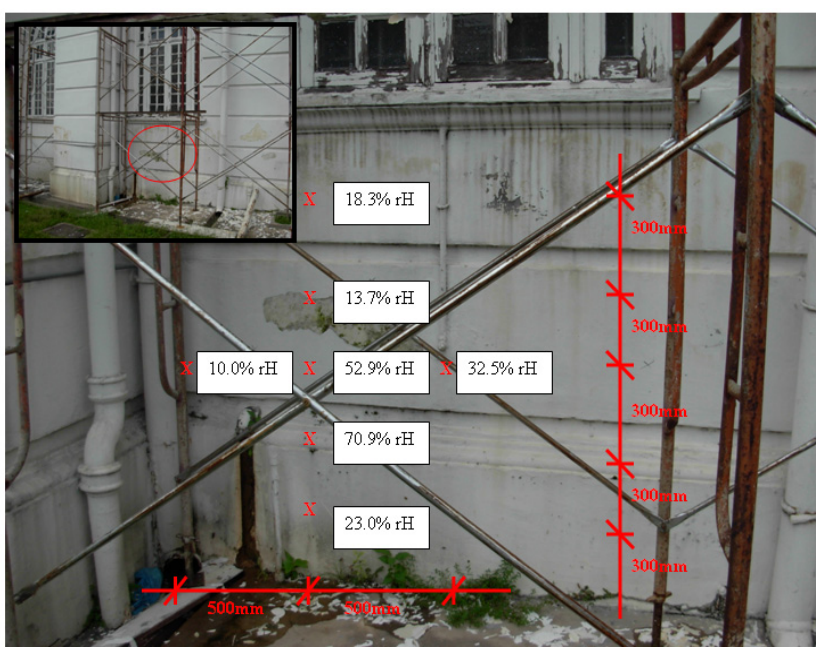

Grid: B/2 (Y10), Checklist 26

Photo 4.9 Location of Pipe Leakage

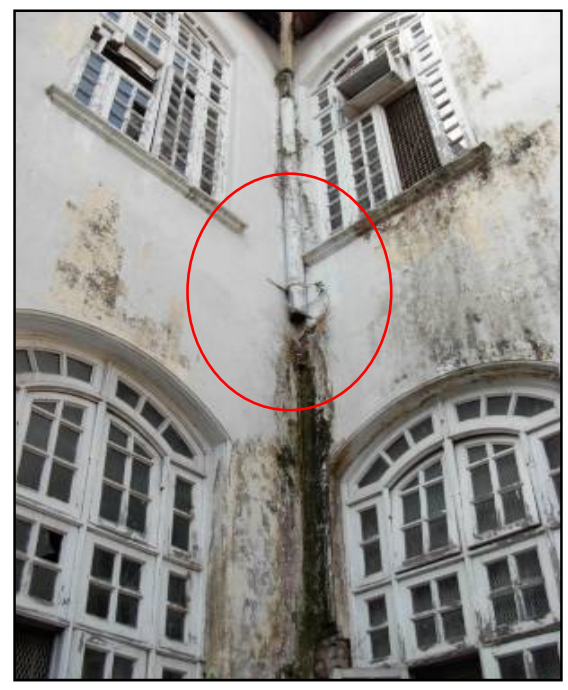

Grid: D/8 (Y3) ), Checklist 19

Photo 4.8 Fungus Attack

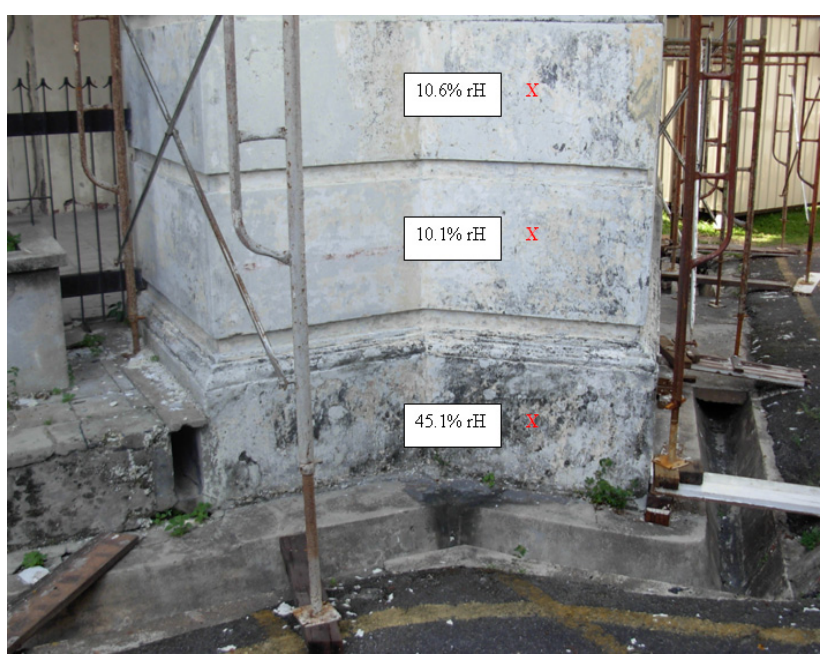

Grid: G/12 (TL4) ), Checklist 31

Photo 4.10 Location of Driving Rain

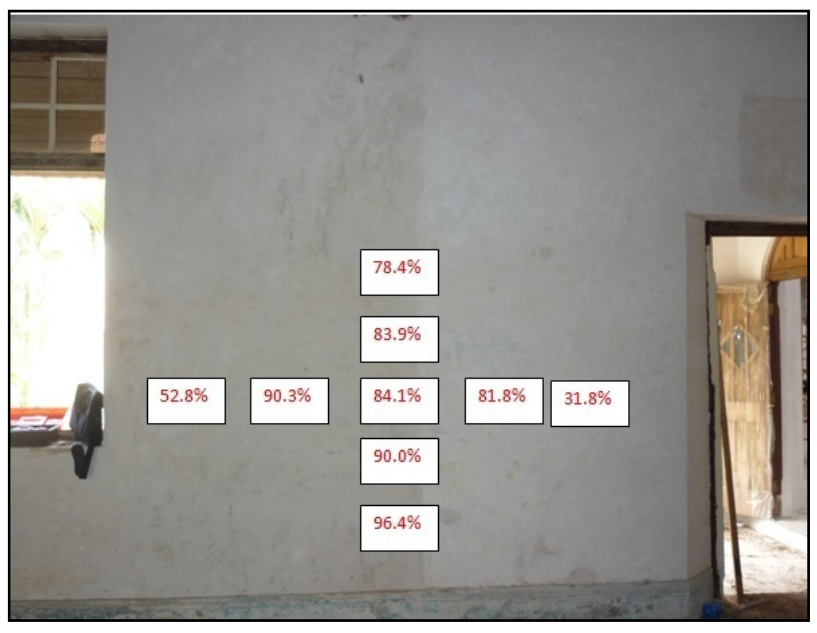

Photo 5.1 Dampness at Internal Wall Caused by Roof Leakage 

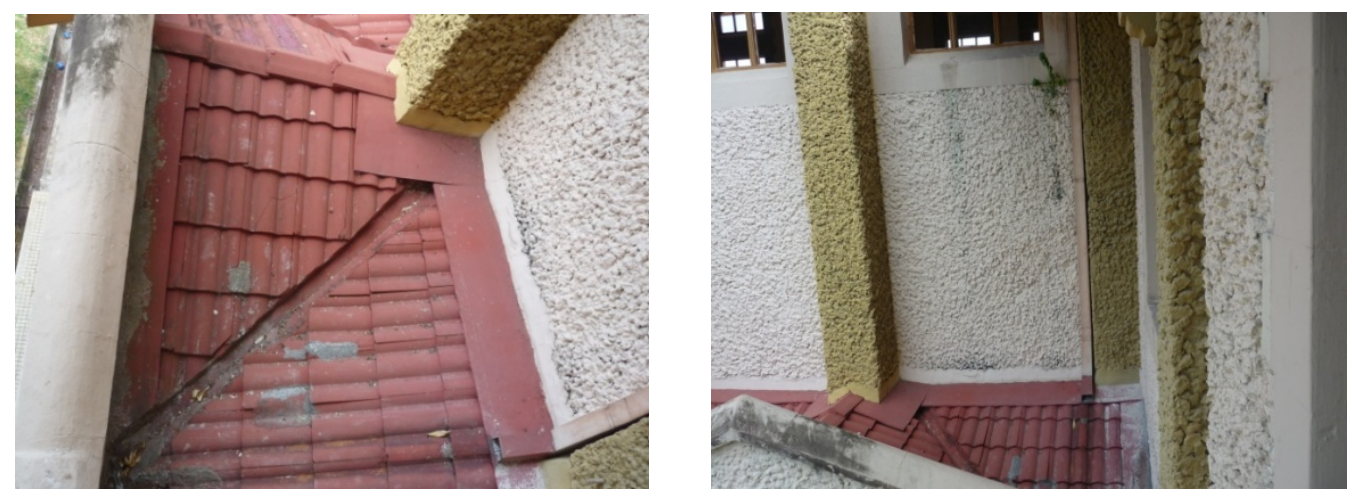

Photos 5.2 Defective Rainwater Goods

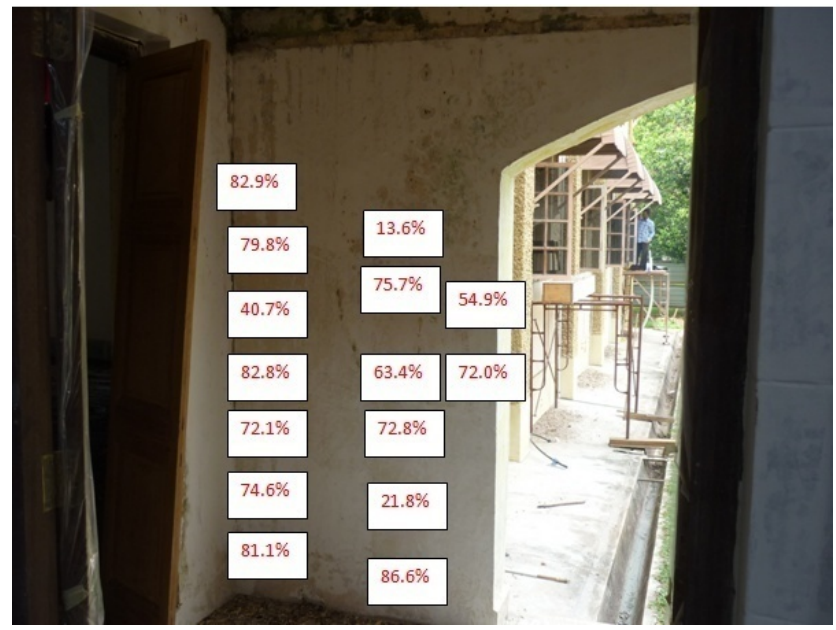

Photo 5.3 High Moisture Content Caused By Water Penetration
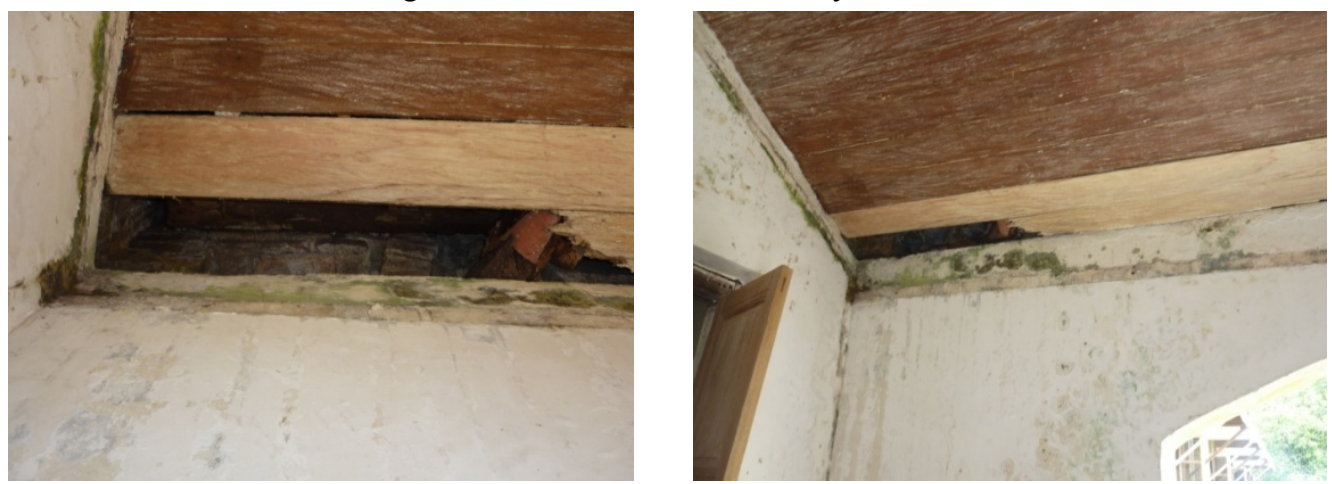

Photos 5.4 Moss, Fungus and Ceiling Decay
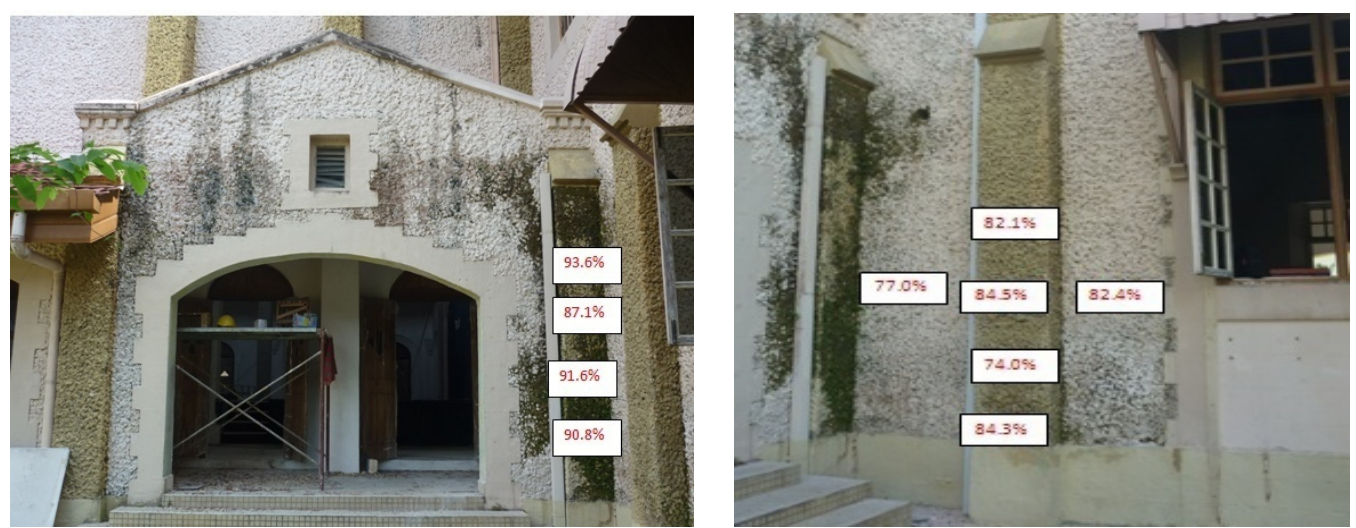

Photos 5.5 Moss and Black Staining Occur on the Surface of Wall 


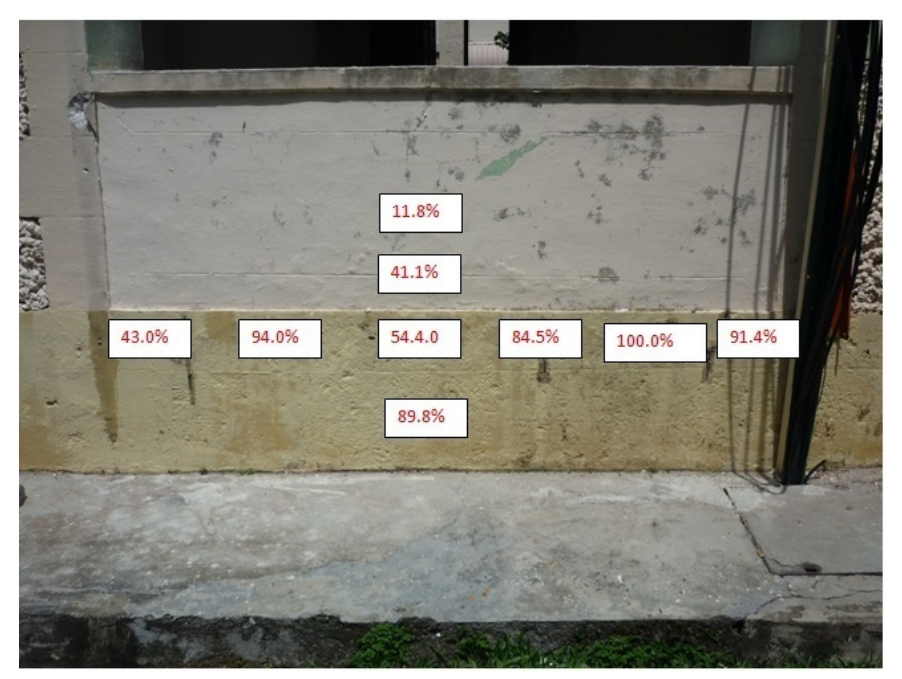

Photo 5.6 Rising Damp
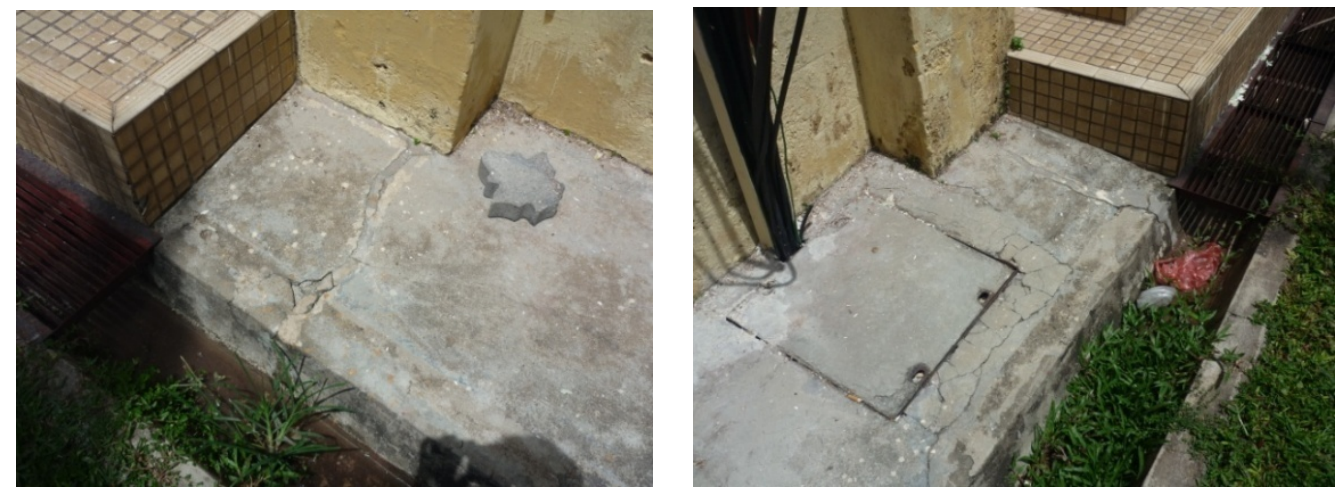

Photos 5.7 Broken Drainage and Cracking at Apron

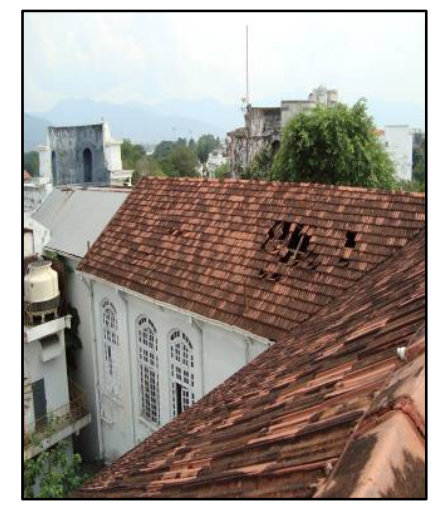

Photo 6.1

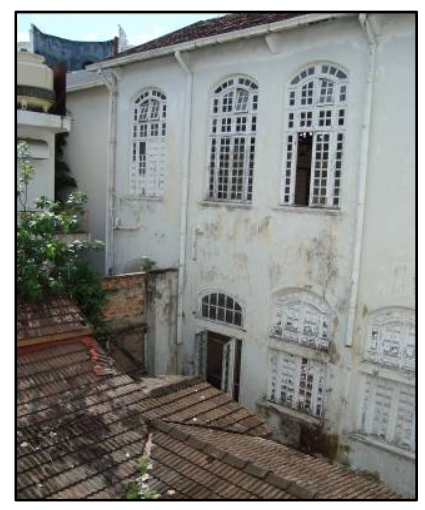

Photo 6.2

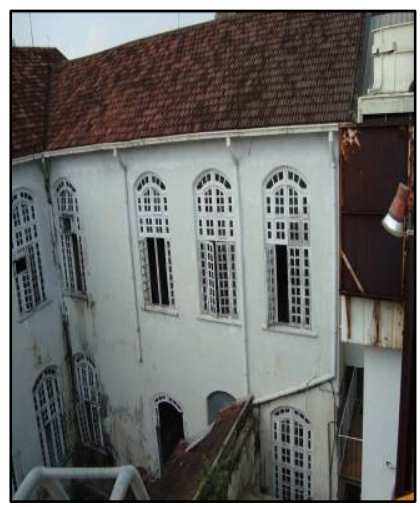

Photo 6.3 


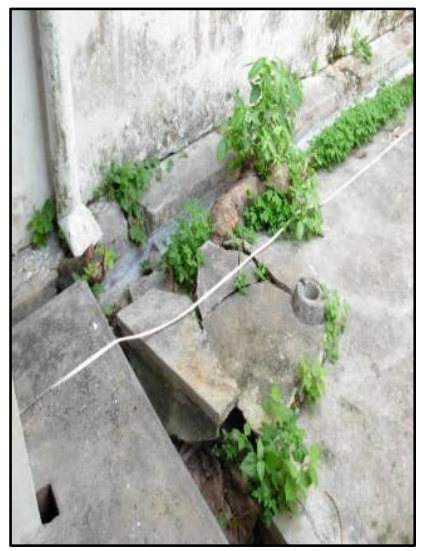

Photo 6.4

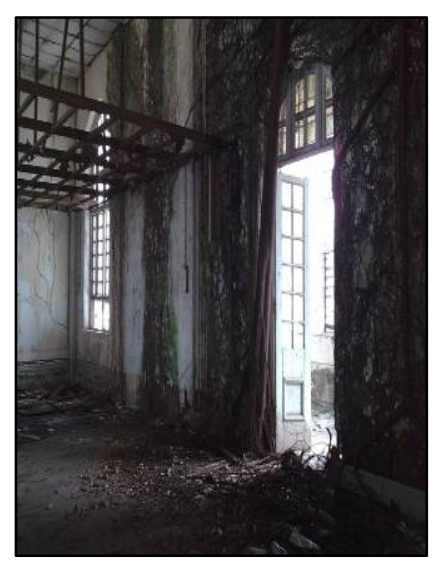

Photo 6.7

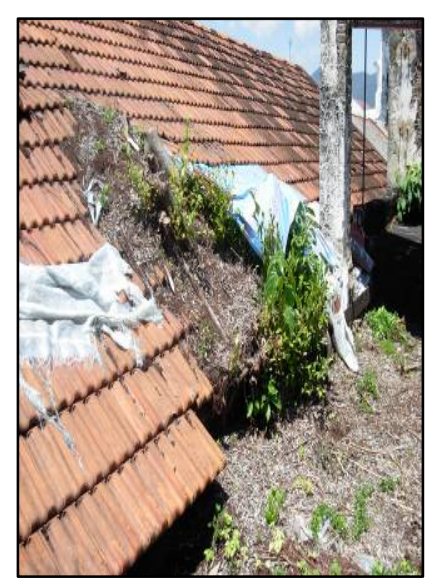

Photo 6.10

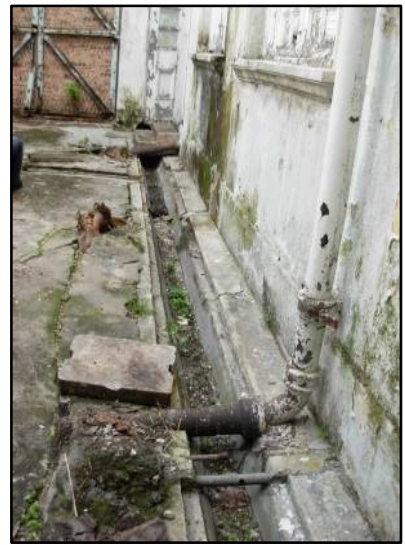

Photo 6.5

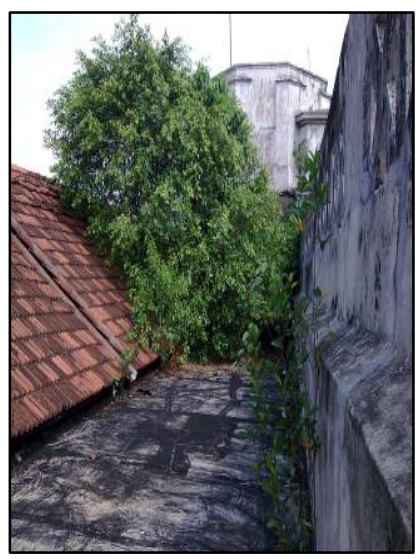

Photo 6.8

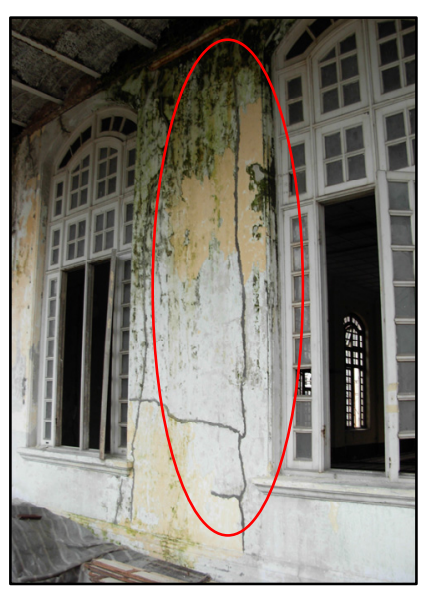

Photo 6.11

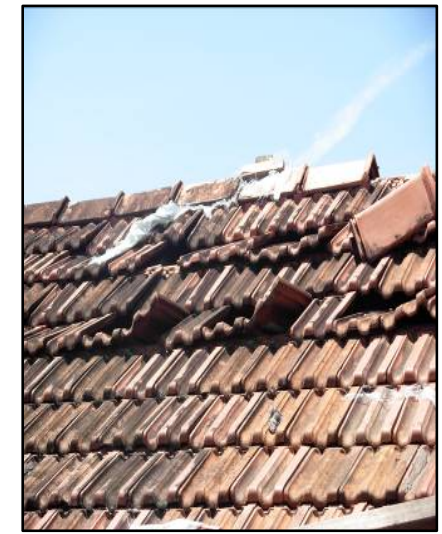

Photo 6.6

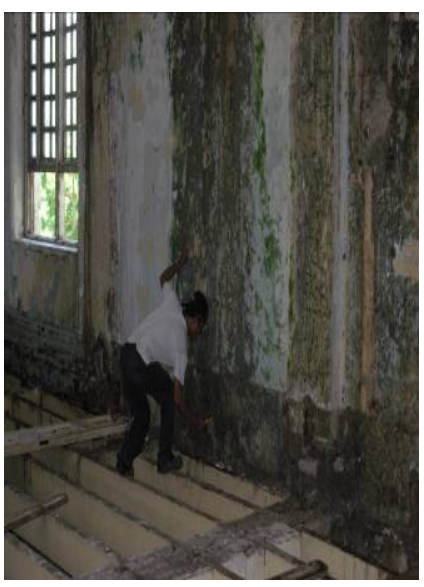

Photo 6.9

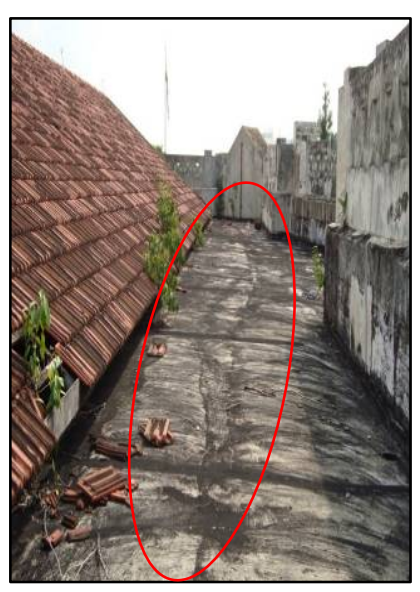

Photo 6.12 